\title{
A clouded view of Europe's demographic future
}

\section{Paul Demeny*}

The European Commission's report on the demographic future of Europe (European Commission 2006) is an earnest and well-intentioned document. Perhaps it is too unkind to follow up that characterisation with a reminder of the proverb: the road to hell is paved with good intentions. The document's very brevity - grossly disproportionate to the weight of its subject — might be cited as an excuse for the title not living up to its promise. Still, it seems to me, a court of demographers would judge the document seriously flawed. It offers a clouded picture of what Europe's demographic future is, or should be, and the "challenges and opportunities" it identifies largely miss their target. The document's failings, I think, are fourfold. (1) It is oblivious of the issue of population size and growth; (2) it is clueless about fertility policy; (3) it is clear-eyed about policies needed to address population ageing, but fails to draw the main lesson from its own prescriptions; and, finally, (4) it is incoherent in its treatment of the issue of immigration. Because of the limitation of space, I will address in some detail only the first two of these topics. My remarks on the third and fourth points, even though they pose crucial questions about Europe's demographic future, will be perfunctory.

\section{Population size and growth}

The size of a population and its rate of change are key concerns of demography and of political economy. It is inappropriate and irresponsible to discuss Europe's demographic future - indeed, Europe's future tout court-without considering population size and growth. The Commission's report effectively ignores them. It does so with a slight of hand. It presents a Eurostat projection that shows the EU-25 population in 2005 and 2050 and treats it as Scripture. The picture offered is essentially one of stasis. The "total population of the EU-25 will fall slightly," says the Commission. (I added the italics.) "Slightly" is correct: the difference is a mere 2 per cent. The prospect of a stationary state has an obvious appeal; it appears to obviate the need to reflect upon the issue of population size. To quickly pass on to discussing structure - population ageing - is then entirely appropriate.

But that prophesied happy population stasis is cooked: it is achieved by the assumption of net immigration to the EU of "around 40 million." Where does this figure come from? Not from some scientific insight, much less from judicious

\footnotetext{
* Paul Demeny, Population Council, One Dag Hammarskjöld Plaza, New York, NY 10017, USA
} 
calculation of what the EU countries' immigration policies might generate in terms of immigrant numbers. The report calls the immigration figure "conservative." Then why did Eurostat pick this conservative figure? The likely answer is that it wished to fill the gap - in part country-by-country, but at least for the EU as a whole - between the population size that a projection to 2050 would produce in the absence of migration and the present population of the EU. Eurostat, I conjecture, has an implicit assumption about the right size of Europe's population: it should stay pretty much what it is today.

The concept of optimum population has an antiquated air about it; modern demographers avoid it like the devil the holy water. Indeed, we do not know what optimum population size is, nor can we successfully nail down its first cousin, the optimum rate of population growth. But that does not absolve the Commission from ignoring the issue of size and growth in a paper making pronouncements on Europe's demographic future. I will not fill in for what the Commission missed, but I can at least illustrate the nature of the issue.

In round figures, in 1950, the countries that today constitute EU-27 had a population of 370 million. In 2005, they had a population of 490 million. Thus the absolute growth, registered over a period of 55 years, was roughly 120 million, equivalent to absorbing the inhabitants of another present-day France and Britain combined. This makes the average yearly growth rate a modest-looking one-half per cent. Consider now the question: would Europeans be happy to contemplate adding yet another 120 million persons by 2060 to their (as some not necessarily malicious observers might put it) already overcrowded home-a beautiful but smallish peninsula attached to the western end of the Eurasian mainland? Or, would they be pleased about the prospect of continuing demographic expansion at the annual .5 per cent clip, so as to reach a population of 645 million not quite two generations hence? These counterfactual questions may seem absurd: such growth is not in the cards. Yet the questions are worth asking and answering, even if tentatively. Would such growth render the EU, by any historical comparison now fabulously rich, richer yet? Richer, that is, per capita - the correct measure to gauge riches for large population aggregates. Would that larger population size, amplified by greater affluence, be in harmony with Europeans' taste for the good life, in particular with their preferences regarding environmental amenities, living space, and "footprint"?

And would Europe's demographic weight and influence increase within the wide world, should such growth ensue? We know the answer about weight: it would not. Europe cannot compete with the rest of the continents in terms of population size and growth. Even superficial familiarity with, say, the UN medium projections, would confirm that. Between 2005 and 2050, according to the UN, India alone will add 524 million to its population. Africa will add more than a billion. The demographic race to regain Europe's one-time share within the world total has been lost, and what is lost irretrievably need not be bemoaned. It should be assessed and coped with. Yes, Europe could catch up with China some 
time in the twenty-second century if its demographic growth as experienced in the past 55 years were to continue into the future. But would Europe want to engage in such a race even if it could? Would it be worth it?

As to influence, the best one can say is that it is not, need not be, primarily a function of population size. What Europe, along with its then young overseas daughters, contributed in science, technology, art, and political thought and institutional design in the long nineteenth century ending with 1914-by most reckoning Europe's best ever - gave shape, and largely continues to give shape, to the modern world. Yet that creative Europe had a population of less than 300 million on the eve of the first World War-counting in terms of a sort of imagined EU-30+: one excluding Russia and its then possessions of Slavic lands. Numbers alone do not a civilisation make, nor in the main account for its influence beyond its borders.

Europe has also pioneered in, and set an example for the rest of the world in, changing secular patterns of demographic behaviour. With death rates down and still falling, birth rates had to follow. The time gap between these two processes produces growth that might create population sizes greater than what is in the best collective interest of a society - a near-inevitable concomitant of the pattern of demographic transition. In this regard, too, Europe was exemplary: there, institutions, popular tastes, and the "wisdom of the crowds" performed better in keeping demographic overshoot, if that is the right name for it, less extravagant than was the case elsewhere in the world. But, slow or speedy during the transition, population growth eventually has to stop, and to do so by means of lower fertility, if low mortality and high material standards of living are to prevail. That the necessary downward adjustment of fertility in turn can produce an overshoot below replacement levels is unsurprising and, in a longer term perspective, plausibly both salutary and self-correcting. Europe is experiencing the consequences of this second type of overshoot. It now has an increasing number of followers, fellow-overshooters elsewhere in the world. Eventually, the pattern set by Europe will have to become global.

This brings us back to the real prospects of Europe with respect to population size and growth. The Commission, preoccupied with age structure, failed to confront the twin issues of shrinking size and negative growth. The right numerical reference in starting to think about these variables, their drawbacks and merits, and about what, if anything, policies ought to do to influence them, is population projection, country-by-country and for the EU as a whole, in the absence of migration. Filling-in the gaps in size and growth by a suitable number of immigrants so as to produce the false semblance of a prospective nearstationarity short-circuits policy analysis. First should come contemplation of natural population dynamics, then examination of possible corrective action. Unlike fertility and mortality, migration is supposed to be a wholly policydetermined variable, not a force of nature. Are smaller population numbers and population shrinkage tolerable for, or even welcome in, Europe? Or are they 
harmful or even disastrous? Are there ways of adjusting to these changes, while coming out ahead in terms of welfare? And if European countries do not like what the wisdom of the crowds implies for their neighbourhood in matters demographic, what combination of measures should be adopted to increase fertility, adjust to population ageing, and attract - or rather, allow entry ofmigrants?

An egregious consequence of ignoring the issue of population size and growth is the report's silence about EU enlargement. Countries' populations expand or shrink as a combined balance of births, deaths, and net immigration. But the European Union also grows by accretion, as was the case most recently in 1989, 1995, 2004, and 2007. Potentially it can also shrink by exit or expulsion, but further enlargement is actually on the EU's current agenda. Croatia is a near-term candidate for membership and eventual admission of several other Balkan countries is generally assumed. This will yield an EU-30+, and more than twentyfive official EU languages, further enhancing what the report rightly calls the Union's "riches of diversity"-although it sees those riches being amassed through immigration. Enlargement is of course first and foremost a political issue, but its demographic dimension is hardly a marginal matter. This is especially clear with respect to Turkey's admission, which is also under active consideration. A decision about it should be demographically informed. By 2015 , Turkey's population, according to the UN's medium projection, would surpass that of Germany, currently the largest member country of the EU. The Union would also acquire its first and only megacity, Istanbul. And demography, as always, comes in a package with geography. With Turkey's admission, the EU would have land borders-Schengen borders? - with such populous Asian countries as Syria, Iraq, and Iran. (Within the next ten years, Iran, too, will have a population that exceeds Germany's.) There are surely "challenges and opportunities" in enlargement. It is perhaps too much to ask the report to pronounce about their balance, but to be silent about the issue in a report titled "The demographic future of Europe"-and for "Europe" read European Unionis pretending to be blind.

\section{Fertility}

The report devotes only a few short paragraphs to policies "promoting demographic renewal in Europe." "Demographic renewal" is evidently intended as a politically correct term, substituting for the dreaded label "pronatalism." The substitution is awkward. Demographic renewal is occurring in Europe as in any other sizable population - one generation, the older, is replaced by another, younger. The problem is the inadequacy of the rate of renewal. This may sound like a quibble; it is sufficiently clear what the Commission is talking about. But it is a bad omen for the success of a policy if its very aim needs to be obfuscated by terminological gymnastics. 
The Commission, supported no doubt by many demographers, sets great store by the notion - "surveys show"! - that "couples would like to have more children" than they actually end up having. There is no reason to doubt the sincerity of such declarations. The problem is that women and couples would like to have, or be occupied and entertained by, many other things besides giving birth and raising children. If they want to visit, say, Bali or the Galapagos Islands, children are a distinct inconvenience. Children then remain Kopfgeburten, as Günter Grass called such intended but unrealised procreation in his comic novel about Germany's birth dearth written more than a quarter century ago. Still, some gap between expressed desire and actual performance does exist and may be narrowed by suitable public policies. The Commission's recipes for effecting such narrowing are utterly conventional, echoing the reigning orthodoxy on the subject. Reduce inequalities of opportunities "offered to citizens" with or without children; socialise the costs of childrearing beyond current practice; and make paid work more compatible with having children.

Whatever the costs and the yields of such measures, the first question is: are they - or any pronatalist policies whatsoever-justified? The Commission does not ask the question, but it should. Answering it calls for distinguishing between differing demographic situations in EU countries. Not all of them meet the test of "reaching a worrying level," the report's stated criterion. In a liberal democracy the starting assumption is that bearing children is essentially a private affair; it is none of the business of the government how many children mothers and families choose to have. Society at large of course has a stake in the aggregate result of those choices - and indeed in the quality with which parents perform their task of raising the children they do elect to have- but intervention would have to meet stringent tests. Even if fertility is below replacement level, there is a fairly broad band-perhaps up to a shortfall of some 0.3 or 0.4 from replacement-level TFRwithin which policies intended to increase the birth rate would rest on very dubious foundations. If sustained, such levels of fertility would eventually lead to negative rates of natural increase, hence to a shrinking and rather aged population. But the resulting decrease would be slow, and a technologically advanced society would be able to adjust with relative ease. Such shrinkage would entail a mixture of pains, such as an economically disadvantageous age structure, and advantages - less crowding, saner environment, smaller footprint. A laissez-faire stance would accept the outcome as the result of what people want as demonstrated by their free fertility choices, and with the expectation that spontaneous feed-back effects would eventually correct the deficiency in full generational replacement. There could be a fairly generous allocation of waiting time for such adjustments to occur: these populations do not face the fate of the Hittites or Sumerians any time soon. But the situation bears watching and should be a recurrent topic of public discourse.

Why relatively high fertility levels prevail in some European countries-in France, in Britain, and in Scandinavia - is of course a contentious matter. Just as 
some observers attribute the fact that women in Asia and Latin America are no longer hell-bent to have seven or more children apiece to wise government programs, politicians in Europe, and not a few demographers, seem to be convinced that in the lucky countries of western and northern Europe fertility is comfortingly close to replacement as a result of wise social policies subsidising parenthood. Cross-country comparisons give little support to such beliefs, but proposing experiments to ascertain the truth is not in the Commission's proposed agenda. Would children remain illiterate and uneducated in the sciences, the humanities, and in plain good manners if European governments did not provide free education and did not collect the taxes that finance schools? The answer is probably no, in fact the results might turn out to be just the reverse, but Europeans are understandably disinclined to find this out. Would the birth rate plummet in France if the state's cherished services to families were to shrink and take-home pay correspondingly to rise? Perhaps yes, but no experiments are likely to be undertaken in this domain. Staying put is the better part of wisdom in such a situation. By the same token, no compelling arguments call for the extension of state services, qua pronatalist measures, in countries where fertility is not much below replacement level. Such policies may respond to popular demand for gestures of social solidarity. But their inefficiency is generally conspicuous, if poorly recognised: the government churns monies from pocket to pocket, by intermediating so Peter can pay some part of the cost of Paul's children and Paul is compelled to reciprocate in kind.

The picture changes in regard to countries experiencing fertility further down, let alone much further down the TFR ladder. Even in these cases, becoming a museum piece like the Aztecs or the Etruscans is far from a near-term prospect, and an unexpected reversal of fertility behaviour sufficient to lift such populations out of the danger zone may be part of the coming evolutionary agenda. Still, with TFRs hovering in the neighbourhood of 1.3 decade after decade, the prospect of rapid population shrinkage and of extreme population ageing should put governments into an increasingly interventionist frame of mind. There, measures that increase the birth rate become public goods in the strict sense of the term: they might perform a valued function that the market — ordinary voluntary social interaction-has failed to provide.

In contemplating what to do, governments of countries with very low fertility would do well to think out of the box, or at least also out of the box, into which the Commission sees "renewal" policies neatly packageable. This is not the place to elaborate on possible measures. But options outside the familiar armamentarium of pronatalist policies that have not been tried have considerable promise. They would seek structural reforms that would not rely primarily on dispensing money and services. Rather, they would seek to change institutional arrangements so as to reestablish and reinforce parental responsibility for and authority over children; to strengthen the economic security of women within the family; allow parents to benefit directly from having raised children (such as 
through reallocation of social security contributions of working persons in existing pay-as-you-go arrangements directly to their living parents); and to make the political system more responsive to the young generation's interests (for example, by granting extra voting rights to adults for their minor children, or, more effectively, in a bicameral legislature, by allocating voting rights in the upper chamber according to average expectation of life at the voter's agetechnologically feasible using an electronic voting system).

As to the Commission's (and many governments') emphasis on the goal of making work outside the home compatible with childrearing, that intent is salutary and should be pursued. But taken as a central facet of pronatalist measures its appropriateness is highly questionable. Save among the very rich, its success would tend to result in a parity distribution dominated by two-child families - or, in general, by women with two children with or without a male partner - supplemented by a smaller fraction of couples and women with only one child or no child at all. Higher parity women would likely become very rare, far from counterbalancing parities zero and one. Having three, four, or more children is full-time work, hardly compatible with outside paid employment. Neither would such compatibility be in the interest of children, hence of society at large. Thus the proposed policy would lock in a sub-replacement average fertility. But women, or indeed men, are not uniform in their life-style preferences. A minority, and presumably not a negligible minority, would likely prefer large families if that were affordable-large not in the style of Johann Sebastian Bach's, but four or five children, well above the contemporary norm. Institutional arrangements could be designed that would make fulfillment of such preferences realisable, with appropriate safeguards as to the quality of home environment for the children. This, bluntly, requires fully paid parenthood for one of the parents, paid at rates fully competitive with labour market rates that the subsidised person could obtain, given her or his personal qualifications. The financing of the scheme could in most cases be entirely secured by terminating current collectively financed services and subsidies and Zapatero-style baby bonuses which now pay for childbearing and childrearing that in the overwhelming majority of cases would be forthcoming even in the absence of the subsidy.

What are the chances that political capacity exists in very low-fertility states to carry out an effective pronatalist agenda? Despite their potentially dire demographic predicament, the answer is simple: very small. One reason for this is that action on social policy issues framed within national borders will become less and less relevant and feasible within the EU at large. In that broader community, Italians, like Swedes, will more likely to look to a London-based insurance company (whose diversified portfolio might consist mostly of Chinese or African investments) for their old-age pension than to their "local" governments. In that future Europe, by virtue of their forebears' voluntary fertility behaviour, some families, regions, and ethnicities will simply find themselves to be more or less numerously represented. In relative terms, there might be fewer Spaniards and 
more Frenchmen, fewer Bulgarians and more Irishmen - just as nowadays within the UK Scots elect to be increasingly less numerous than do Englishmen. Laissezfaire in the matter of fertility may once again rule. The prospect for returning to population replacement in a demographically smaller sized, but richer and quite possibly happier and wiser Europe would be uncertain, but far from implausible. Still, it would be good if the Commission returned to its "demographic renewal" agenda and undertook a careful rethinking of its diagnosis and its proposed remedies.

\section{Population ageing}

Europe's coming confrontation with a rapidly ageing population structure occupies the main part in the Commission's report. The difficult problems of adjusting to that inevitable, and fundamentally positive, change are crisply and accurately stated and so are the needed responses. There are no surprises here: what needs to be done has been spelled out again and again in an unceasing flow of books, reports, policy briefs, and learned speeches. The problem is difficult but can be solved. The terms of the generational bargain must be revised, state pension systems must be reformed, age of retirement has to be extended in line with progressive lengthening of life expectancy. Labour force participation rates must be raised and so must be the quality of the labour force and, with it, productivity. When and if substantial progress is achieved in these directions, demographic ageing recedes as a dominant impediment to continuing economic progress. The report clearly states that immigration makes only a modest and ephemeral contribution to the solution of the ageing problem. When the report turns to the discussion of migration itself the implications of that finding are, however, forgotten.

\section{Immigration}

The Commission's treatment of immigration from outside the EU is incoherent and irresponsible. That international migration is a normal component of global society is to be taken for granted. Some European scientists, entrepreneurs, artists, and businessmen might want to move to and settle in China, India, or Saudi Arabia and perhaps they would be allowed to do so. In line with its long historical tradition, Europe would be reasonably expected to extend a similar if even more broad-minded welcome. But such flows, important as they may be in the economic and cultural interaction among nations, are demographically insignificant. The issue that has a bearing on Europe's demographic future is the overall scale of such migration. "Europe is already the recipient of major inflows of net migrants from third countries," says the Commission. Indeed it is, which might raise the question whether an extended pause to absorb and culturally assimilate those tens of millions of recent immigrants would not be in order. Would Integrationsgipfels be more conducive to good outcomes if Germany were to take in another 9 million migrants by 2050 as Eurostat says it will? And what 
risks of social tensions and transformations will be associated with the posited inflows elsewhere in Europe? Does Britain need 5 million more immigrants; must its nurses be imported from Sierra Leone and Ghana? Is it plausible to assume, as Eurostat does, that net immigration rates will be much higher in Greece, Austria, Sweden, the Netherlands, Hungary, and the Czech Republic, than in France? And if the Eurostat-assumed 40 million net immigration to the EU between 2005 and 2050 is as "conservative" a figure as the Commission thinks it is -indeed 40 million is just 1.5 per cent of the expected net addition to the population of the less developed world during that period - what number of immigrants would the Commission consider as more realistic, one that would also be "respecting the needs of the countries of origin"?

"The EU is set to remain a popular destination for migrants in the coming decades," says the Commission report as an explanation of the "conservatively" estimated influx, thus implying that the size of the coming immigration is determined not by policies formulated in EU capitals (which, at least within the Schengen zone, would need general consensus among members) but by a passive response to supply. "For the countries of origin, immigration to the EU can be beneficial." But the demographic and economic problems which fuel that migration will not be solved even by a volume of migration that could radically change European societies: the sender countries' solution must be domestic. Yet Europe's continuing admittance of masses of migrants will no doubt eventually be grounds for the senders to claim parasitic exploitation of developing countries. "We must not ignore the possibilities offered by temporary migration and the voluntary return of migrants to their countries of origin," says the Commission's report, as if the contrary experience of the 1950s and 1960s were fully erased from European memory, or as if Europe would be prepared to accommodate a Helot subpopulation along the lines set by the example of the Emirates.

These and a host of other issues pertinent to immigration are not examined by the report even though it acknowledges that the receiving countries' economic gain would be marginal. The Commission would do well to reflect upon the story of Esau as told in Genesis. Should Europe sell its birthright for a mess of pottage? The question is valid, even if that precious birthright was not earned through personal merit, but simply reflects the luck of choosing one's ancestors and birthplace well.

\section{Reference}

European Commission. 2006. The demographic future of Europe - From challenge to opportunity, Communication of 12 October 2006 [COM (2006) 571]. Available at «http://ec.europa.eu/employment_social/news/2006/oct/demography_en.pdf». 